\title{
Detraining of exercise-trained rats: effects on energetic efficiency and brown adipose tissue thermogenesis
}

\author{
BY JEFF ARNOLD AND DENIS RICHARD* \\ Département de Physiologie, Faculté de Médecine, \\ Université Laval, Québec GIK 7P4, Canada
}

(Received 19 August 1986 - Accepted 13 November 1986)

\begin{abstract}
1. Complete energy balance measurements were made in exercise-trained (treadmill running) rats subjected to $27 \mathrm{~d}$ of exercise detraining.

2. The $20 \%$ difference in body-weight that existed at the end of the training period between sedentary and trained rats was negated by detraining. Detrained rats had twice the body-weight gain of their untrained controls.

3. An elevation $(12 \%)$ in metabolizable energy (ME) intake (relative to body-weight) was observed in detrained rats while their gross energetic efficiency was augmented by $60 \%$.

4. Energy expenditure, excluding the estimated costs of fat and protein storage, was similar for detrained and untrained rats. Complementing the latter was the finding that thermogenesis in brown adipose tissue, a known energy buffering process, was also similar.

5. Elevated ME intake (relative to body-weight) largely contributed to the increased energetic efficiency of detrained rats.
\end{abstract}

Accelerated body-weight gain, arising through increased rates of both fat and protein deposition, is one of the commonly reported modifications that occurs in exercise-trained rats that are subjected to a prolonged period of exercise detraining (Booth et al. 1974; Dohm et al. 1977). Existing reports (Dohm et al. 1977) also indicate that rats undergoing detraining do not consume a greater quantity of food than their untrained controls. These observations, combined with the assumption that nutrient absorption from the gastrointestinal tract is unchanged, suggest an increase in energetic efficiency in rats during the period following cessation of regular exercise training.

With the absence of a difference in energy intake it would appear that the next step toward understanding the augmented energetic efficiency of detrained rats would be to examine their energy expenditure. Assuming that extraneous factors are equal, a lower energy expenditure in detrained rats would in effect indicate the presence of an energy-sparing mechanism. This spared energy would then obviously result in improved energetic efficiency.

Energy sparing may occur within many different physiological processes but one that has obtained a substantial amount of attention in recent years is regulatory thermogenesis. Defective thermoregulatory thermogenesis has been labelled as the instigating factor behind the development of obesity in $o b / o b$ mice (Trayhurn, 1984). In addition, suppression of thermogenesis, as a strategy to promote energy conservation, has been reported to occur in lactating (Trayhurn \& Richard, 1985), food-restricted (Rothwell et al. 1982) and fasted (Hayashi \& Nagasaka, 1983) rodents.

Little information is available regarding the energetics of detraining and to our knowledge there have been no previous studies reporting full energy balance measurements for detrained animals. The present energy balance study was thus conducted to provide insight into the mechanism by which exercise-trained rats potentially increase their energetic efficiency during a period of detraining. As brown adipose tissue (BAT) is acknowledged as being one of the main sites of regulatory thermogenesis (both cold- (Foster \& Frydman,

\footnotetext{
* For reprints.
} 
1978) and diet- (Rothwell \& Stock, 1979) induced) in the rat, thermogenic properties of this tissue were evaluated.

\section{MATERIALS AND METHODS}

Forty-four male Wistar rats (Canadian Breeding Laboratories, St Constant, Quebec), weighing approximately $205 \mathrm{~g}$ at the start of the experiment (approximately 8 weeks old), were placed into three groups. A baseline (initial) group of eight rats was killed immediately and frozen $\left(-20^{\circ}\right)$ pending carcass analysis to provide information about initial body energy and composition. The remaining rats were randomly allocated to two preliminary groups of eighteen each and were housed individually in wire-mesh cages suspended above absorbent paper. All animals were maintained on a $12 \mathrm{~h}$ light-12 h dark cycle (lights on $06.30-18.30$ hours) at a room temperature of $24 \pm 1^{\circ}$. Rats were provided with water and a commercial laboratory chow (Ralston Purina Co., Indiana, USA) ad lib. throughout the entire experimental period. Food intake, excreta and body-weight of all rats were measured every $2 \mathrm{~d}$. Digestible energy intake and metabolizable energy (ME) intake were calculated as previously reported (Richard et al. 1986).

One of the previously mentioned groups of rats served as a sedentary control whereas the other performed an exercise-training programme. Exercise training, similar to that described by Richard et al. (1986), consisted of treadmill running at $25 \mathrm{~m} / \mathrm{min}, 2 \mathrm{~h} / \mathrm{d}$ conducted $6 \mathrm{~d} /$ week, for a total of $35 \mathrm{~d}$. Following the $35-\mathrm{d}$ training programme, eight rats from each of the sedentary and trained groups were killed (08.00-09.30 hours) by decapitation and then frozen; these slaughtered rats were the sedentary (S) and trained (T) groups respectively. The remaining sedentary (referred to as sedentary-sedentary; SS) and trained (trained-sedentary or detrained; TS) rats were then left inactive in their cages for the following $27 \mathrm{~d}$ detraining period. As mentioned previously, body-weight, food intake and excreta were measured every $2 \mathrm{~d}$. The ten SS and ten TS rats were also killed by decapitation following the detraining period.

As previously described (Richard et al. 1986), all carcasses, including those that had been previously frozen, had the gastrointestinal contents removed and were then autoclaved for $20 \mathrm{~min}$. Thereafter they were homogenized and freeze-dried before measuring total energy content. The energy content of carcasses, as with faeces, was determined by bomb calorimetry (Parr Instrument Co., Illinois, USA). Body protein was calculated after determining carcass nitrogen by a micro-Kjeldahl procedure. The fat values presented may be slightly overestimated due to the method of calculation used; the energy derived from protein was subtracted from total body energy to provide the energy as nonprotein matter (taken to represent fat). It was thus assumed that carbohydrate represents a negligible part of total body energy.

Initial energy, protein and fat contents of $S$ and $T$ rats were estimated from their weight by reference to the baseline group of rats killed at the beginning of the study. Likewise, initial energy, protein and fat contents of SS and TS rats were estimated from their body-weight by referring to the final energy levels and final body compositions measured for the $S$ and $T$ groups of rats respectively.

S, T, SS and TS rats were killed and interscapular BAT was excised and cleaned of adhering white fat and muscle before being blotted dry and tared. The isolated tissue was homogenized in a sucrose buffer solution and mitochondria were then isolated as detailed by Cannon \& Lindberg (1979). Samples of homogenates and mitochondria were taken for protein estimation by a modified Lowry method (Schacterle \& Pollack, 1973) with defatted bovine serum albumin used as standard. GDP-binding was measured at room temperature, as previously detailed (Arnold et al. 1986), by incubating the BAT mitochondria with $10 \mu \mathrm{M}-\left[{ }^{3} \mathrm{H}\right] \mathrm{GDP}$ for $7 \mathrm{~min}$ in a medium at $\mathrm{pH} 7 \cdot 1$. 


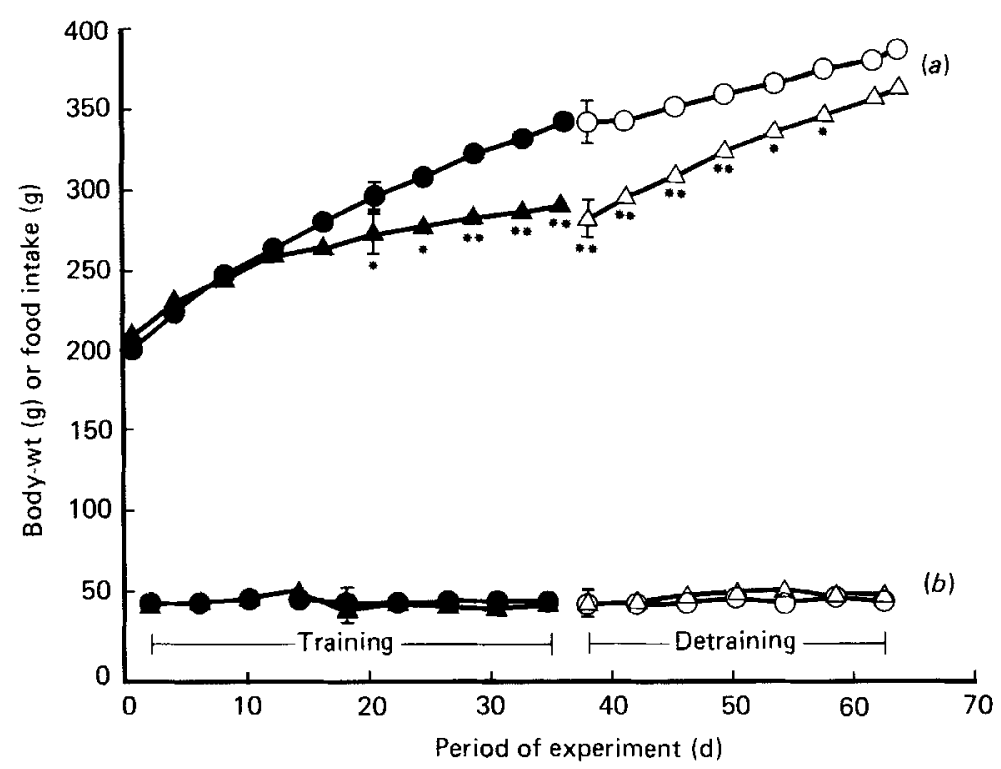

Fig. 1. (a) Body-weight and (b) food intake (g/2 d period) of sedentary $(\boldsymbol{O}, n 8)$ and trained $(\boldsymbol{A}, n 8)$ rats during the $35 \mathrm{~d}$ exercise-training period, and sedentary-sedentary $(O, n 7)$ and trained-sedentary $(\triangle, n 10)$ rats during the $27 \mathrm{~d}$ exercise-detraining period. Points are means with their standard errors represented by vertical bars. Body-weight values for sedentary and sedentary-sedentary rats were significantly different from those for trained and trained-sedentary rats respectively: ${ }^{*} P<0.05$ $* * P<0.01$.

All values presented for $S$ and $T$ rats are for the period covering the $35 \mathrm{~d}$ training programme. Estimation of the energy cost of the exercise-training programme for $T$ rats was based on calorimetrically determined values (averages) from a previous study (Arnold $\&$ Richard, 1987). Briefly, total $\mathrm{O}_{2}$ (litres) consumed during exercise was calculated as total running time $(\mathrm{min}) \times$ average body-weight $(\mathrm{kg}) \times$ exercise $\mathrm{O}_{2}$ consumption (above resting metabolic rate) ( $\mathrm{ml} / \mathrm{kg}$ per $\mathrm{min}$ ). The latter values $(\mathrm{ml} / \mathrm{kg}$ per $\mathrm{min}$ ) (Arnold \& Richard, 1986) were obtained from air samples taken while rats ran for 120 min within a treadmilladapted metabolism chamber at $25 \mathrm{~m} / \mathrm{min}$. Total $\mathrm{O}_{2}$ (litres) consumed during the exercise programme was converted to units of work using a kilojoule equivalent of $20.9 \mathrm{~kJ} / 1 \mathrm{O}_{2}$. Values shown for SS and TS rats are only those which were collected for the $27 \mathrm{~d}$ detraining period. Values expressed relative to body-weight were calculated using an average of the body-weights from each $2 \mathrm{~d}$ measurement period. Results were statistically evaluated by Student's $t$ test (non-paired) (Hays, 1981). Values are shown as means with their standard errors.

\section{RESULTS}

As seen in Fig. $1(b)$ during the training period, food intake was similar for $\mathrm{T}$ and $\mathrm{S}$ rats; both groups consumed on average $46 \mathrm{~g}$ chow during every $2 \mathrm{~d}$ period. Likewise, food intake was also similar for both groups of rats during the detraining period. As anticipated, body-weight (Fig. 1(a)) became significantly lower in T animals following $20 \mathrm{~d}$ of exercise and continued as such until completion of the training programme. Thus TS (detrained) rats commenced the detraining period with a body-weight $22 \%$ lower than that of their 
Table 1. Effects of exercise training and detraining on protein and fat gains

(Mean values with the standard errors; no. of rats in parentheses)

\begin{tabular}{|c|c|c|c|c|c|c|c|c|}
\hline & \multicolumn{4}{|c|}{ Training $\dagger^{\dagger}$} & \multicolumn{4}{|c|}{ Detraining $\ddagger$} \\
\hline & \multicolumn{2}{|c|}{ Sedentary (8) } & \multicolumn{2}{|c|}{ Trained (8) } & \multicolumn{2}{|c|}{$\begin{array}{c}\text { Sedentary- } \\
\text { sedentary (7) }\end{array}$} & \multicolumn{2}{|c|}{$\begin{array}{c}\text { Trained- } \\
\text { sedentary }(10)\end{array}$} \\
\hline & Mean & SE & Mean & $\mathrm{SE}$ & Mean & SE & Mean & $\mathrm{SE}$ \\
\hline Initial body protein $(\mathrm{g})$ & $34 \cdot 9$ & 0.5 & $36 \cdot 3$ & $0 \cdot 6$ & $63 \cdot 4$ & $2 \cdot 1$ & $53 \cdot 4^{* *}$ & 0.9 \\
\hline Final body protein $(\mathrm{g})$ & $63 \cdot 4$ & $2 \cdot 1$ & $55 \cdot 0^{* *}$ & $0 \cdot 9$ & $75 \cdot 0$ & $2 \cdot 1$ & $70 \cdot 0^{*}$ & 1.0 \\
\hline Protein gain $(\mathrm{g})$ & $28 \cdot 5$ & $1 \cdot 8$ & $18 \cdot 7^{* *}$ & $1 \cdot 1$ & $11 \cdot 6$ & $0 \cdot 8$ & $16 \cdot 6^{* *}$ & $0 \cdot 7$ \\
\hline Initial body fat $(\mathrm{g})$ & $14 \cdot 5$ & $0 \cdot 3$ & $15 \cdot 4$ & $0 \cdot 4$ & $36 \cdot 3$ & 1.9 & $18 \cdot 3^{* *}$ & $0 \cdot 2$ \\
\hline Final body fat (g) & $36 \cdot 3$ & $2 \cdot 5$ & $18 \cdot 0^{* *}$ & $0 \cdot 9$ & $46 \cdot 4$ & $1 \cdot 4$ & $34 \cdot 4^{* *}$ & $2 \cdot 3$ \\
\hline Fat gain $(\mathrm{g})$ & $21 \cdot 9$ & $2 \cdot 4$ & $2 \cdot 6^{* *}$ & $0 \cdot 9$ & $10 \cdot 0$ & $0 \cdot 6$ & $16 \cdot 1^{* *}$ & 0.7 \\
\hline
\end{tabular}

Value were significantly different from corresponding control group (Student's $t$ test): ${ }^{*} P<0.05,{ }^{* *} P<0.01$.

$\dagger$ Values from the $35 \mathrm{~d}$ training period.

$\ddagger$ Values from the $27 \mathrm{~d}$ detraining period.

Table 2. Energy balance in sedentary and exercise-trained rats for the $35 d$ training period (Mean values with their standard errors for eight rats per group)

\begin{tabular}{|c|c|c|c|c|}
\hline & \multicolumn{4}{|c|}{ Training } \\
\hline & \multicolumn{2}{|c|}{ Sedentary } & \multicolumn{2}{|c|}{ Trained } \\
\hline & Mean & $\mathrm{SE}$ & Mean & $\mathbf{S E}$ \\
\hline \multicolumn{5}{|l|}{ Metabolizable energy intake: } \\
\hline $\mathrm{kJ}$ & 10500 & 235 & 9802 & 176 \\
\hline $\mathrm{kJ} / \mathrm{kg} \mathrm{W}^{0.75}$ per $\mathrm{d}$ & 771 & 7 & 758 & 10 \\
\hline 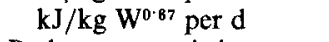 & 697 & 6 & 681 & 9 \\
\hline \multicolumn{5}{|l|}{ Body energy gain $\uparrow$ : } \\
\hline $\mathrm{kJ}$ & 1496 & 128 & $522^{* *}$ & 44 \\
\hline $\mathrm{kJ} / \mathrm{kg} \mathrm{W}^{0.75}$ per $\mathrm{d}$ & 109 & 8 & $40^{* *}$ & 4 \\
\hline $\mathrm{kJ} / \mathrm{kg} \mathrm{W}^{0.67}$ per d & 99 & 7 & $36^{* *}$ & 3 \\
\hline Gross efficiency + & $0 \cdot 14$ & 0.01 & $0.05^{* *}$ & 0.01 \\
\hline $\begin{array}{l}\text { Net energy cost of exercise } \\
\text { training }(\mathrm{kJ})\end{array}$ & - & & 745 & 11 \\
\hline \multicolumn{5}{|l|}{$\begin{array}{l}\text { Energy expenditure excluding } \\
\text { the net cost of exercise } \| \text { : }\end{array}$} \\
\hline $\mathrm{kJ}$ & 9005 & 173 & 8534 & 191 \\
\hline $\mathrm{kJ} / \mathrm{kg} \mathrm{W}^{0.75}$ per $\mathrm{d}$ & 662 & 8 & 660 & 12 \\
\hline $\mathrm{kJ} / \mathrm{kg} \mathrm{W} \mathrm{W}^{0.67}$ per $\mathrm{d}$ & 598 & 7 & 593 & 11 \\
\hline
\end{tabular}

W, body-weight.

Mean values were significantly different from those for the sedentary rats: $* * P<0.01$.

$\uparrow$ Values of $22.4 \mathrm{~kJ} / \mathrm{g}$ and $39.2 \mathrm{~kJ} / \mathrm{g}$ were taken for the energy content of protein and fat respectively (Davidson et al. 1975).

¥ Gross efficiency was calculated as body energy gain/metabolizable energy intake.

$\S$ The net cost of exercise training (energy expenditure above resting metabolic rate) was based on calorimetrically determined values in a previous study (Arnold \& Richard, 1987).

$\|$ Energy expenditure was calculated as metabolizable energy intake-body energy gain. 
Table 3. Energy balance in sedentary and exercise-detrained rats for the 27 detraining period

(Mean values with their standard errors; no of animals in parentheses)

\begin{tabular}{|c|c|c|c|c|}
\hline & \multicolumn{4}{|c|}{ Detraining } \\
\hline & \multicolumn{2}{|c|}{ Sedentary-sedentary (7) } & \multicolumn{2}{|c|}{ Trained-sedentary (10) } \\
\hline & Mean & $\mathrm{SE}$ & Mean & SE \\
\hline \multicolumn{5}{|l|}{ Metabolizable energy intake: } \\
\hline $\mathrm{kJ}$ & 8069 & 171 & 8326 & 136 \\
\hline $\mathrm{kJ} / \mathrm{kg} \mathrm{W}^{0 \cdot 75}$ per $\mathrm{d}$ & 639 & 5 & $715^{* *}$ & 7 \\
\hline $\mathrm{kJ} / \mathrm{kg} \mathrm{W}^{0.67}$ per d & 589 & 5 & $654^{* *}$ & 6 \\
\hline \multicolumn{5}{|l|}{ Body energy gain } \\
\hline kJ & 650 & 63 & $1102^{* *}$ & 84 \\
\hline $\mathrm{kJ} / \mathrm{kg} \mathrm{W}^{0 \cdot 75}$ per $\mathrm{d}$ & 52 & 6 & $94 * *$ & 6 \\
\hline $\mathrm{kJ} / \mathrm{kg} \mathrm{W}^{0.67}$ per d & 48 & 5 & $86^{* *}$ & 6 \\
\hline Gross efficiency $\ddagger$ & $0 \cdot 08$ & 0.01 & $0 \cdot 13^{*}$ & 0.01 \\
\hline \multicolumn{5}{|l|}{ Energy expenditure\$: } \\
\hline $\mathrm{kJ}$ & 7418 & 224 & 7224 & 96 \\
\hline $\mathrm{kJ} / \mathrm{kg} \mathrm{W}^{0.75}$ per d & 587 & 10 & $621^{*}$ & 9 \\
\hline $\mathrm{kJ} / \mathrm{kg} \mathrm{W}^{0.87}$ per d & 541 & 9 & $568^{*}$ & 8 \\
\hline Heat loss in storing protein and fat $\|(\mathrm{kJ})$ & 466 & 31 & $691^{* *}$ & 39 \\
\hline \multicolumn{5}{|l|}{$\begin{array}{l}\text { Energy expenditure excluding } \\
\text { heat loss in storing protein and fat } \$ \text { : }\end{array}$} \\
\hline $\mathrm{kJ}$ & 6952 & 246 & 6533 & 89 \\
\hline $\mathrm{kJ} / \mathrm{kg} \mathrm{W}^{0.75}$ per $\mathrm{d}$ & 550 & 12 & 562 & 9 \\
\hline $\mathrm{kJ} / \mathrm{kg} \mathrm{W}^{0.67}$ per $\mathrm{d}$ & 507 & 12 & 513 & 8 \\
\hline
\end{tabular}

W, body-weight.

Mean values were significantly different from those for the sedentary-sedentary rats: ${ }^{*} P<0.05,{ }^{* *} P<0.01$.

$\dagger$ Values of $22.4 \mathrm{~kJ} / \mathrm{g}$ and $39.2 \mathrm{~kJ} / \mathrm{g}$ were taken for the energy content of protein and fat respectively (Davidson et al. 1975).

$\ddagger$ Gross efficiency was calculated as body energy gain/metabolizable energy intake.

$\S$ Energy expenditure was calculated as metabolizable energy intake-body energy gain.

Values of 1.25 and $0.36 \mathrm{~kJ} / \mathrm{kJ}$ were used to estimate heat loss in storing protein and fat respectively (Pullar \& Webster, 1977).

untrained (SS) controls. However, after completion of the $27 \mathrm{~d}$ of detraining, body-weight was observed to be equal in TS and SS rats; detrained animals displayed a near doubling in body-weight gain compared with that of their controls.

Table 1 shows the effects of exercise training and detraining on body composition. Exercise caused a sharp decline in both protein and fat gains; in comparison with the gains observed in their $S$ controls, exercise-trained $(T)$ rats showed decreases in protein and fat gains of 34 and $88 \%$ respectively. On commencing detraining, body protein and fat levels were 16 and $50 \%$ lower respectively in TS rats compared with their controls. However, at the time of killing, body protein and fat levels of TS rats were lower by only 7 and $26 \%$ respectively, compared with SS control rats.

Table 2 shows energy balance values for the $35 \mathrm{~d}$ training period. The $7 \%$ lower $\mathrm{ME}$ intake (kJ) of T compared with $\mathrm{S}$ rats was not statistically significant. Likewise, ME intake relative to body-weight also remained similar between the two groups. Both body energy gain and gross efficiency were decreased with exercise training; the latter variables were almost three times lower in $\mathrm{T} v$. S rats. Energy expenditure, corrected for the cost of exercise training, was observed to be similar whether expressed relative to body-weight or in absolute (kJ) terms.

Table 3 shows energy balance measurements for the $27 \mathrm{~d}$ detraining period. ME intakes 

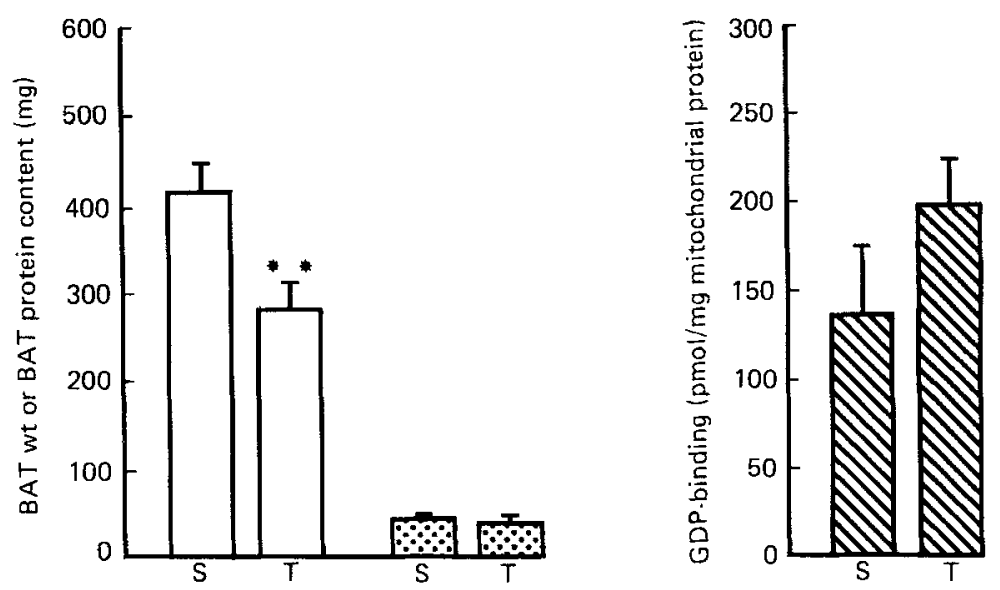

Fig. 2. Brown adipose tissue (BAT) weight ( $\square$ ), total BAT protein content (囼) and GDP-binding (\$) in sedentary $(\mathrm{S}, n 8)$ and exercise-trained $(\mathrm{T}, n 8)$ rats. Values are means with their standard errors represented by vertical bars. Values for $T$ rats were significantly different from those for $S$ rats: ${ }^{* *} P<0.01$.

were not significantly different for TS and SS rats, when expressed in absolute terms (kJ). However, when expressed relative to body-weights, the ME intake in detrained animals was significantly greater. Body energy gain and gross efficiency were a little more than 1-5-fold higher in TS compared with SS rats. Calculated energy expenditure, relative to body-weight, was seen to be significantly higher in TS rats. However, after subtracting the energy associated with protein and fat storage, energy expenditure expressed in absolute or relative terms was not significantly different between TS and SS groups of rats.

Fig. 2 shows some characteristics of BAT from S and T rats. Physical activity reduced both the weight and total protein content of this tissue. The $20 \%$ lower total protein content in BAT of $\mathrm{T}$ rats compared with $\mathrm{S}$ rats was not significant. GDP-binding by BAT mitochondria was unaltered by the exercise-training programme.

Fig. 3 shows characteristics of BAT from TS and SS rats. Total protein content of BAT was very similar for TS and SS rats despite a $13 \%$ greater tissue weight in SS animals. There was no difference in GDP-binding by BAT mitochondria between TS and SS rats.

\section{DISCUSSION}

The present results confirm those of past studies that have also shown a reduction of protein and fat gains in exercising male rats (Oscai, 1973; Richard et al. 1986). The reduced body energy gain of exercised rats in the present study appears to have resulted largely from their increased energy expenditure (due to physical activity), that was not compensated by an increase in food intake. Although food intake was not significantly altered in our exercise-trained rats, reduction in food intake has previously been reported to contribute, in addition to the cost of exercise, to decreased body energy gains in trained rats (Crews et al. 1969; Richard et al. 1986).

Energy expenditure (after allowing for the cost of exercise), expressed relative to body-weight or in absolute terms, was similar for exercise-trained and sedentary rats. In addition, BAT thermogenesis was also found to remain unchanged by exercise training, a finding that is consistent with previous observations made in this laboratory (Richard 

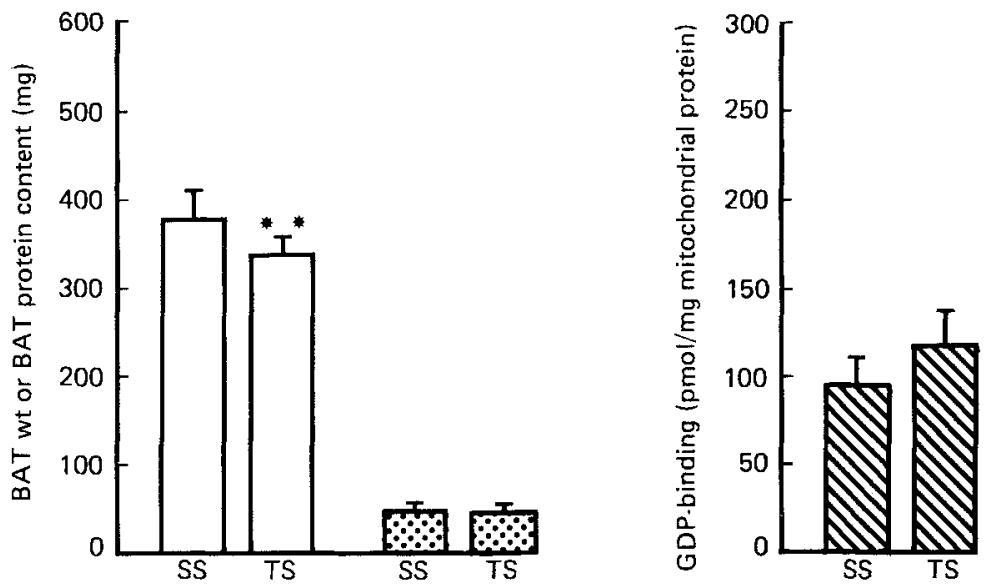

Fig. 3. Brown adipose tissue (BAT) weight ( $\square$ ), total BAT protein content (圈) and GDP-binding ( in sedentary-sedentary (SS, $n$ 7) and trained-sedentary (TS, $n$ 10) (exercise-detrained) rats. Values are means with their standard errors represented by vertical bars. Values for TS rats were significantly different from those for SS rats: $* * P<0 \cdot 01$.

et al. 1986). Therefore, the present and recently reported (Richard et al. 1986) results provide evidence that expenditure components, such as regulatory diet-induced thermogenesis and thermoregulatory thermogenesis, are not altered with exercise training. However, at this point, one must acknowledge a certain limitation with the calculation of energy expenditure; energy expenditure as such represents the sum of all expenditure components and thus each component cannot be reliably quantified.

Little knowledge exists concerning the mechanism that permits trained-detrained rats to gain more body-weight than control rats while consuming equal amounts of food. A previous study measuring food intake in detraining rats failed to express food intake relative to body-weight (Dohm et al. 1977). Due to differences in body-weight between the various groups of rats it would seem that a better interpretation of energy intake, and energy expenditure, would be provided by expressing these results relative to the metabolic body size ( $\mathrm{kg}$ body-weight $(\mathrm{W})^{0 \cdot 75}$ ), or perhaps according to a more adequate expression for intraspecific energy metabolism, $\mathrm{kg} \mathrm{W}^{0.67}$ (Heusner, 1985). Expressed as such, ME intake in the present study was more than $10 \%$ higher in detrained rats.

In the present study the energy content of faeces $(\mathrm{kJ} / \mathrm{g})$ was similar for TS and SS rats. Previously, Dohm et al. (1977) found no difference in faecal protein, carbohydrate and lipid levels with detraining. Thus it may be surmized that detrained (TS) rats do not absorb more nutrients (energy) per portion of food than control rats.

Energy expenditure, expressed relative to body-weight, was found to be significantly greater in TS rats. However, as energy gain was likewise elevated in these same rats and as all rats were sedentary during the detraining period, it was assumed justifiable to deduct the energy cost of storage from the overall energy expenditure before comparing detrained rats with their untrained controls. After correcting energy expenditure for the differences in storage costs, TS and SS rats were found to have similar energy expenditures.

In detraining rats, the absence of an energy-sparing mechanism, such as reduced regulatory thermogenesis, was also confirmed by our assessment of BAT thermogenesis; BAT mitochondrial proton conductance pathway activity, as evaluated by GDP-binding, was unaltered in detrained rats. 
An approximate $40 \%$ decrease in gross efficiency was observed in the SS rats during the detraining period when compared with the younger $S$ rats. One possible explanation for this change in efficiency may relate to the age of the rats. As rats age both energy intake and energy deposition decrease. In fact, energy deposition decreases more rapidly than energy intake; energy intake remains higher to presumably compensate for the larger cost of maintenance. Consequently an index based on the ratio of energy gain: total energy intake inevitably decreases with age and would approach zero as energy gain plateaus.

The experiments conducted by Hill et al. $(1984,1985)$ examined the effects of energy restriction on energy utilization in rats and can be compared to the present study of detraining. Both groups examined the energy metabolism of rats with reduced body-weight gains, be it diet- or exercise-induced. In the work of Hill et al. $(1984,1985)$ it was observed that rats with reduced body-weight, due to underfeeding, reduced maintenance energy requirements in proportion to their reduction in body-weight. More specifically, it may be proposed from the latter work that underfed rats, due to their smaller body-weight would also have a proportionally lower basal metabolic rate.

In summary, cessation of exercise training resulted in a near complete reversal of the exercise effects on body composition; body fat and protein levels approached, in a catch-up manner, those levels in untrained controls following $27 \mathrm{~d}$ of detraining. During the detraining period no alteration in energy expenditure, excluding storage costs, was observed. Rather, the accelerated body-weight gain and hence increased energetic efficiency of detrained rats was largely due to their increased energy intake (relative to body-weight).

The authors thank Josée Lalonde and Pierrette Simpson for their meticulous assistance.

\section{REFERENCES}

Arnold, J. D., LeBlane, J., Côté, J., Lalonde, J.\& Richard, D. (1986). Canadian Journal of Physiology and Pharmacology 64, 922-926.

Arnold, J. D. \& Richard, D. (1987). American Journal of Physiology (In the Press).

Booth, M. A., Booth, M. J. \& Taylor, A. W. (1974). Federation Proceedings 33, 1959-1963.

Cannon, B. \& Lindberg, O. (1979). Methods in Enzymology 55, 65-78.

Crews, E. L., Fuge, K. W., Oscai, L. B., Holloszy, J. O. \& Shank, R. E. (1969). American Journal of Physiology 216, 359-363.

Davidson, S., Passmore, R., Brock, J. F. \& Truswell, A. S. (1975). Human Nutrition and Dietetics. 6th ed. Edinburgh: Churchill Livingstone.

Dohm, G. L., Barakat, H. A., Tapscott, E. B. \& Beecher, G. R. (1977). Proceedings of the Society for Experimental Biology and Medicine 155, 157-159.

Foster, D. O. \& Frydman, M. L. (1978). Canadian Journal of Physiology and Pharmacology 56, 110-122.

Hayashi, M. \& Nagasaka, T. (1983). American Journal of Physiology 245, E582-E586.

Hays, W. L. (1981). Statistics, 3rd ed. London: Holt, Rinehart and Winston.

Heusner, A. A. (1985). Annual Review of Nutrition 5, 267-293.

Hill, J. O., Fried, S. K. \& DiGirolamo, M. (1984). American Journal of Physiology 247, R318-R327.

Hill, J. O., Latiff, A. \& DiGirolamo, M. (1985). American Journal of Physiology 248, R549-R559.

Oscai, L. B. (1973). Exercise and Sport Sciences Reviews, vol. 1, pp. 103-123 [J. H. Wilmore, editor]. New York Academic Press.

Pullar, J. D. \& Webster, A. J. F. (1977). British Journal of Nutrition 37, 355-363.

Richard, D., Arnold, J. \& LeBlanc, J. (1986). Journal of Applied Physiology 60, 1054-1059.

Rothwell, N. J., Saville, M. E. \& Stock, M. J. (1982). Bioscience Reports 2, 543-549.

Rothwell, N. J. \& Stock, M. J. (1979). Nature 281, 31-35.

Schacterle, G. R. \& Pollack, L. R. (1973). Analytical Biochemistry 51, 654-655.

Trayhurn, P. (1984). Clinical Endocrinology and Metabolism 13, 451-475.

Trayhurn, P. \& Richard, D. (1985). Biochemical Society Transactions 13, 826-828. 